\title{
Análise dos espaços de circulação e permanência de pedestres (ECPP) em relação ao escoamento superficial das águas pluviais: Estudo de caso de uma área residencial localizada em São José do Rio Preto/SP.
}

Analysis of spaces circulation and permanence of pedestrians (ECPP) in relation to runoff of rainwater: study case of a residential area located in Sao Jose do Rio Preto/ SP.

Análisis de la circulación y permanencia de los espacios de peatones (ECPP) en relación a la escorrentía del agua de lluvia: estudio de caso de una zona residencial ubicada en Sao Jose do Rio Preto / SP.

Geovana Geloni Parra Mestre pelo Programa de Pós-Graduação em Engenharia Urbana, UFSCar, Brasil geovanaparra@terra.com.br

Bernardo Arantes do Nascimento Teixeira Professor Doutor, UFSCAR, Brasil. bernardo@ufscar.br 


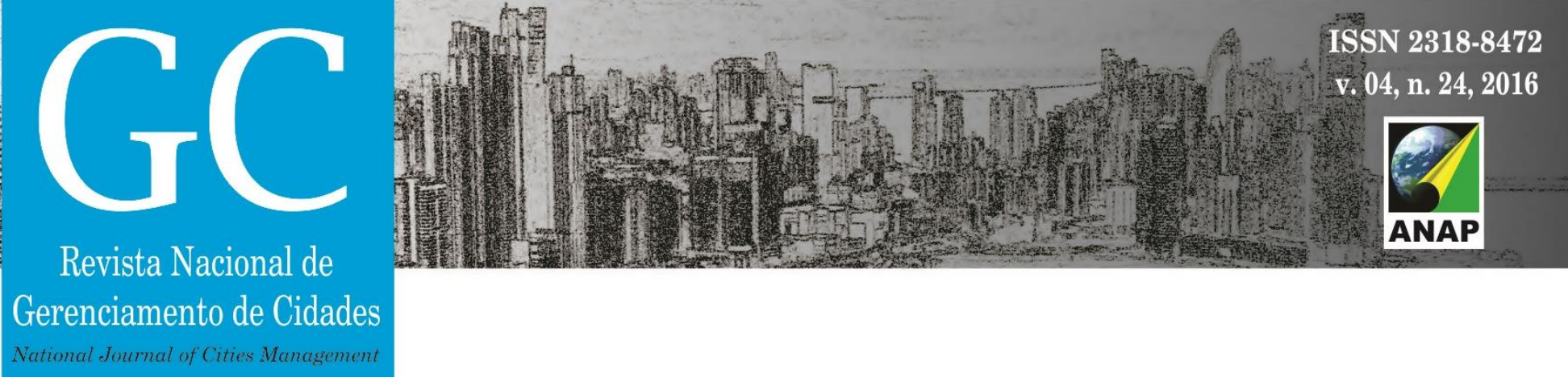

RESUMO

A alta impermeabilização do solo urbano tem contribuído cada vez mais para a ocorrência de enchentes, em alguns casos a área impermeabilizada destinada aos pedestres pode ser significativa. $O$ objetivo deste trabalho foi quantificar e diagnosticar a contribuição para o escoamento superficial dos Espaços de Circulação e Permanência de Pedestres (ECPP) localizados em uma área residencial de São José do Rio Preto/SP. O bairro residencial escolhido possui técnica compensatória de drenagem urbana e atende especificações de "calçadas verdes". Após análise do projeto e caracterização dos pavimentos foram calculados os valores teóricos do escoamento superficial, e determinados três cenários de estudo, o Real, o Favorável, onde o escoamento é direcionado para as faixas gramadas e o Desfavorável, onde todos os ECPPs estão impermeabilizados. Os resultados mostraram que o cenário Real dos ECPPs contribuem igualmente ao cenário Desfavorável, totalmente impermeabilizado, o que indica que a população não tem seguido a legislação especifica.

PALAVRAS-CHAVE: Drenagem urbana, Espaços de Circulação e Permanência de Pedestres (ECPP), pavimentação, impermeabilização, escoamento superficial.

\section{ABSTRACT}

The high waterproofing of urban soil has contributed increasingly to flooding occurrence, in some cases the waterproofing area intended to pedestrians can be significant. The goal of this research was quantify and diagnose the contribution to runoff of the Spaces of Circulation and Permanence Pedestrians (ECPP) located in a residential area in São José do Rio Preto/SP. The neiborhood chosen compensatory technique of urban drainage and meets specifications of "green sidewalks." After project and characterization analysis pavement were calculated the theorist values runoff, and certain studies three scenarios, real, favorable, the runoff is directed to the grassy tracks and scenario Unfavorable, where all the ECPPs are waterproofing. The results showed that real scenario of ECPPs contribute equally the unfavorable scenario, all waterproofing, that indicates the population it has not followed the specific legislation.

KEYWORDS: Urban drainage, Spaces of Circulation and Permanence Pedestrians (ECPP), pavement, waterproofing, runoff.

\section{RESUMEN}

La alta impermeabilización de suelo urbano cada vez más ha contribuido a la aparición de inundación, en algunos casos la zona de impermeabilización destinado a los peatones puede ser significativo. El objetivo de este trabajo fue cuantificar y diagnosticar la contribución a la escorrentía de los espacios de circulación y peatones de permanencia (ECPP), ubicado en una zona residencial en São José do Rio Preto / SP. La técnica elegida alrededores compensatorio de drenaje urbano y cumple con las especificaciones de "aceras verdes". Después de proyectos y análisis de caracterización de pavimento se calcularon los valores de la segunda vuelta teórico, y ciertos estudios de tres escenarios, bienes, favorable, la escorrentía se dirige a las pistas de hierba y escenario desfavorable, en el que todos los ECPPs se impermeabilización. Los resultados mostraron que escenario real de ECPPs contribuyen igualmente el escenario desfavorable, todo impermeabilización, que indica la población a la que no ha seguido la legislación específica.

PALABRAS-CLAVE: Drenaje urbano, espacios de circulación y peatones de permanencia (ECPP), pavimento, impermeabilización, la escorrentía. 
com intensidade de $111,9 \mathrm{~mm} / \mathrm{h}$, e obteve o coeficiente de escoamento de solo compactado igual a 0,66, pavimento impermeável (concreto) igual a 0,95, pavimento semipermeável (blocos de concreto igual a 0,78 e paralelepípedos igual a 0,6) e pavimento permeável (blocos de concreto vazado) igual a 0,03 .

Um estudo realizado por Moura (2005), teve como objetivo comparar e quantificar a eficiência de superfícies permeáveis. $O$ trabalho apresenta o comportamento de 4 tipos de superfícies permeáveis: grama, chão batido, blocos maciços e blocos vazados. Foi utilizado para experiência uma área de $1 \mathrm{~m}^{2}$ para cada tipo de superfície, onde foram feitas simulações de chuva para avaliar o comportamento do escoamento e da infiltração em cada uma delas, como apresentado na Tabela 1:

Tabela 1: Tabela da Média dos dados da taxa média de infiltração encontrados no estudo experimental realizado

\begin{tabular}{lcccccc}
\hline $\begin{array}{l}\text { Tipo de } \\
\text { Superfície }\end{array}$ & $\begin{array}{c}\text { Solo } \\
\text { gramado }\end{array}$ & $\begin{array}{c}\text { Chão } \\
\text { batido }\end{array}$ & $\begin{array}{c}\text { Bloco maciço s/ } \\
\text { compactação }\end{array}$ & $\begin{array}{c}\text { Bloco maciço c/ } \\
\text { compactação }\end{array}$ & $\begin{array}{c}\text { Bloco vazado s/ } \\
\text { compactação }\end{array}$ & $\begin{array}{c}\text { Bloco vazado c/ } \\
\text { compactação }\end{array}$ \\
\hline $\begin{array}{c}\text { Média da } \\
\text { Taxa de } \\
\text { Infiltração }\end{array}$ & 103,5 & 51 & 59 & 24,5 & 93 & 53 \\
\hline $\begin{array}{c}\text { Média do } \\
\text { Coeficiente } \\
\text { de }\end{array}$ & 0,21 & 0,57 & 0,63 & 0,72 & 0,2 & 0,51 \\
Escoamento & & & & & \\
\hline
\end{tabular}

Fonte: Moura (2005)

Já a pesquisa realizada por Bruno et al.(2013) também avalia experimentalmente as seguintes estruturas: solo gramado, solo exposto, blocos de concreto maciço, blocos de concreto vazado e piso de concreto convencional, com simulação de chuva. Para uma intensidade de precipitação de $79 \mathrm{~mm} / \mathrm{h}$ o solo gramado apresentou infiltração total, o solo exposto $29,15 \mathrm{~mm} / \mathrm{h}$, os blocos de concreto maciço $78,07 \mathrm{~mm} / \mathrm{h}$ e o concreto convencional $3,11 \mathrm{~mm} / \mathrm{h}$.

A manutenção dos pisos permeáveis é muito importante visto que quando a estrutura colmata, ela para de infiltrar, aumentando a taxa de escoamento superficial. Barbosa e Moura(2014), analisaram a vida útil da permeabilidade dos pavimentos permeáveis para 15 anos, pois estas estruturas estão sujeitas a colmatação ao longo do tempo de uso. Os ensaios foram realizados com base na norma ASTM C1701, com teste em pavimentos permeáveis de 40\% de área livre, em 13 locais da cidade de Belo Horizonte/MG, sendo estacionamentos e postos de combustíveis. Os resultados encontrados mostram que quanto mais novo o pavimento maior a taxa de infiltração e que com o passar dos anos esta taxa de infiltração se estabiliza, tornando-se constante.

Wang et al. (2010) encontraram resultados que avaliam a aplicação de pavimentos permeáveis em calçadas quanto aos benefícios térmicos e de redução do escoamento de água de chuva.

Com esses exemplos e com as normas que devem ser seguidas, é possível integrar a acessibilidade e execução dos ECPP, com as vantagens hidrológicas da utilização de 


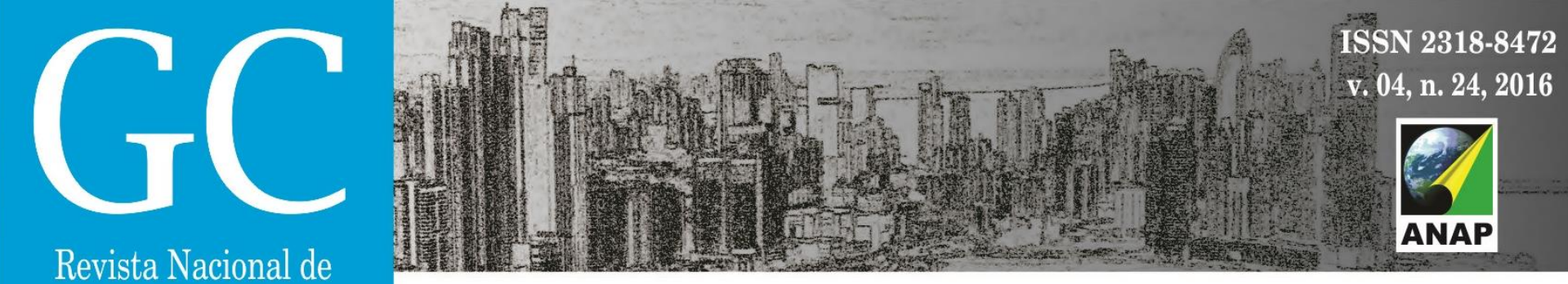

Gerenciamento de Cidades

pavimentos permeáveis ou drenantes, ou ainda assim o desenho dos ECPP integrados a áreas verdes, que facilitam a infiltração das águas de chuva.

Também foram verificados os dados obtidos em catálogos técnicos de fabricantes, e feito uma média de permeabilidade, a partir dos índices encontrados conforme a Tabela 2:

Tabela 2: Tabela de Características de pisos drenantes a partir da informação de fornecedores

\begin{tabular}{|c|c|c|c|c|}
\hline \multirow{2}{*}{$\begin{array}{c}\text { Tipo de Superfície } \\
\text { Fornecedor }\end{array}$} & \multicolumn{4}{|c|}{ Pavimento poroso/drenante } \\
\hline & 1-modelo1 & 1-modelo 2 & 1-modelo 3 & 2 \\
\hline Espessura $(\mathrm{cm})$ & \multicolumn{4}{|c|}{8} \\
\hline Permeabilidade $(\mathrm{mm} / \mathrm{h})$ & 6357 & 13821 & 5107 & 15786 \\
\hline Dimensões(cm) & $20 \times 10 \times 8$ & $20 \times 20 \times 8$ & $40 \times 40 \times 8$ & $50 \times 50 \times 8$ \\
\hline Tráfego & \multicolumn{3}{|c|}{$\begin{array}{l}\text { Pedestres/bicicletas/acesso de } \\
\text { veículos/motocicletas }\end{array}$} & $\begin{array}{c}\text { Pedestres/veículos de } \\
\text { passeio/caminhões leves }\end{array}$ \\
\hline
\end{tabular}

Parra e Teixeira (2015), verificaram que os fornecedores utilizam diversas técnicas para o cálculo da permeabilidade dos pisos, entre elas o ensaio do permeâtro e do de aneis de infiltrômetro. Estes ensaios são realizados em laboratório e não consideram o solo como exutório.

\section{DESCRIÇÃO DO ECPP DE ESTUDO}

O ECPP escolhido é o bairro Jardim Indianapolis, localizado em São José do Rio Preto/SP.

São José do Rio Preto, localizada no noroeste do Estado de São Paulo, segundo o Censo 2010 possui 408.258 habitantes, e uma área $431,96 \mathrm{~km}^{2}$. A taxa de densidade demográfica é de 946,53 habitantes $/ \mathrm{km}^{2}$, sendo que na área urbana esta densidade é de $3.211,17 \mathrm{hab} / \mathrm{km}^{2}$, pois a área urbana do município é de120,54km². A pesquisa do IBGE (Censo 2010) estima que em 2014 a população tenha alcançado 438.354 habitantes.

A cidade apresentou grande crescimento urbano nos últimos anos e sofre com gravíssimos problemas de enchentes, no ano de 2010 foram mapeados 10 principais pontos de inundações segundo Parra et al. (2011).

A escolha de um bairro como objeto de estudo, se deve ao fato de este seguir a legislação de parcelamento e uso e ocupação do solo municipal, mostrando assim resultados que se aproximam da maioria das cidades brasileiras.

A escolha deste bairro aconteceu a partir da seleção de loteamentos abertos implantados após a Legislação Municipal 10.822/2010 de 17 de novembro de 2010, que dispõe sobre o Programa 


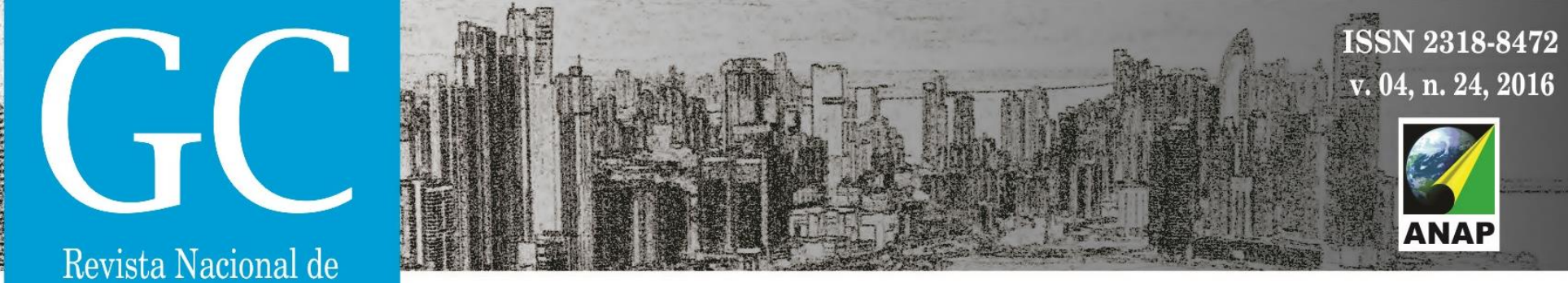

Gerenciamento de Cidades

de Recuperação e Preservação da Permeabilidade do Solo, além do embelezamento do espaço no município de São José do Rio Preto, com a implantação das "Calçadas Verdes", e a Lei Municipal 10.290 de 24 de dezembro de 2008, que cria no município o Programa de Gestão das Águas Superficiais da Bacia Hidrográfica do Rio Preto e da outras providências. Esta lei determina que todas as edificações a serem construídas com área maior que $100 \mathrm{~m}^{2}$ devem possuir dispositivo de retenção ou detenção de águas pluviais, e todo novo empreendimento que importe em parcelamento do solo urbano ou incorporação imobiliária deverá prever na sua implantação o limite de vazão máxima específica. Sendo que toda construção a ser construída em um novo empreendimento que atenda a esta lei, está desobrigada de construir o dispositivo individual de retenção ou detenção de águas pluviais.

O alvará de construção do loteamento é datado do ano de 2008 , e já atendendo a legislação 10.290/2008, a autorização para a construção de edificações ocorreu em 2010, portanto grande parte das construções existentes no local são obrigadas a atender a Lei 10.822/2010.

\section{Diagnóstico físico do espaço}

O projeto do loteamento previu a coleta das águas pluviais em sistema de drenagem convencional, direcionando para bacia de detenção localizada no ponto mais baixo da área. $\mathrm{Na}$ Figura 1 está implantada a bacia de detenção de águas de chuva e a divisão dos lotes.

Foi realizado um levantamento fotográfico no local para verificar as condições dos ECPP existentes, os tipos de pisos, e quais deles atendiam a Lei 10.822/2010, e a partir destes dados uma Tabela descritiva (Tabela 3 ) foi produzida, nela estão descritos os aspectos os aspectos construtivos e de manutenção dos ECPPs. 


\section{Revista Nacional de}

Gerenciamento de Cidades

\begin{tabular}{|c|c|c|c|c|}
\hline \multicolumn{5}{|c|}{ Descrição ECPP Bairro } \\
\hline \multirow{8}{*}{ త্త } & A & $\begin{array}{l}\text { - Calçamento de concreto convencional com faixa } \\
\text { gramada; } \\
\text { - Utilização como estacionamento. }\end{array}$ & $\mathbf{I}$ & $\begin{array}{l}\text { - Calçamento convencional; } \\
\text { - Canteiro central da via sem calçada para pedestres; }\end{array}$ \\
\hline & B & - Calçamento de concreto convencional. & J & $\begin{array}{l}\text { - Espaço não edificado com vegetação alta, cercado, } \\
\text { e sem pavimentação. }\end{array}$ \\
\hline & C & $\begin{array}{l}\text { - Calçamento de concreto convencional; } \\
\text { - Manutenção inadequada; } \\
\text { - Crescimento de vegetação entre rachaduras do } \\
\text { pavimento; } \\
\text { - Bloqueio do passeio por meio de materiais de } \\
\text { construção. }\end{array}$ & $\mathbf{L}$ & $\begin{array}{l}\text { - Calçamento de concreto convencional com faixa } \\
\text { gramada; } \\
\text { - Pisos desnivelados. }\end{array}$ \\
\hline & D & $\begin{array}{l}\text { - Calçamento de concreto convencional com faixa } \\
\text { gramada; } \\
\text { - Espaço bem arborizado; }\end{array}$ & M & $\begin{array}{l}\text { - Calçamento de concreto convencional com faixa } \\
\text { gramada. }\end{array}$ \\
\hline & $\mathbf{E}$ & $\begin{array}{l}\text { - Calçamento de concreto convencional e de cerâmica } \\
\text { com e sem faixa gramada. }\end{array}$ & $\mathbf{N}$ & $\begin{array}{l}\text { - Calçamento de concreto convencional e de } \\
\text { cerâmica com e sem faixa gramada. }\end{array}$ \\
\hline & $\mathbf{F}$ & $\begin{array}{l}\text { - Calçamento de concreto convencional com faixa } \\
\text { gramada. }\end{array}$ & 0 & $\begin{array}{l}\text { - Calçamento em cerâmica, } \\
\text { - Jardim ao invés de faixa gramada. }\end{array}$ \\
\hline & G & - Calçamento de concreto convencional e cerâmica. & $\mathbf{P}$ & $\begin{array}{l}\text { - Calçamento de concreto convencional com faixa } \\
\text { gramada. }\end{array}$ \\
\hline & $\mathbf{H}$ & $\begin{array}{l}\text { - Espaço sem calçamento para pedestres; } \\
\text { - Lixo acumulado na sarjeta; } \\
\text { - Vegetação alta. }\end{array}$ & $\mathbf{Q}$ & $\begin{array}{l}\text { - Calçamento de concreto convencional e de } \\
\text { cerâmica com e sem faixa gramada. }\end{array}$ \\
\hline
\end{tabular}

Após a caracterização do ECPP Bairro, foi demarcada a área (sub-bacia) na Figura 1 com maior números de calçadas verdes existentes no bairro, e realizada a tipologia de pavimentação. 


\section{Revista Nacional de}

Gerenciamento de Cidades

National Journal of Cities Management

\begin{tabular}{l|l|l|l|l|l}
\multicolumn{7}{c}{ Tabela 1-Cenário real microbacia ECPP bairro } \\
$\begin{array}{l}\text { CARACTERÍSTICAS ECPP } \\
\text { BAIRRO }\end{array}$ & $\mathrm{m}^{2}$ & $\%$ & $\begin{array}{l}\text { Coeficiente de } \\
\text { escoamento }\end{array}$ & $\begin{array}{l}\text { Área de Contribuição para } \\
\text { oscoamento superficial } \\
\left(\mathrm{m}^{2}\right)\end{array}$ & $\begin{array}{l}\text { Escoamento } \\
\text { Superficial }\end{array}$ \\
\hline Área Microbacia & $8.721,74$ & $100,0 \%$ & & 7.348 & $84,2 \%$ \\
\hline Lotes Densamente ocupados & $3.475,29$ & $39,8 \%$ & 0,95 & 3.302 & $37,9 \%$ \\
\hline Lotes não ocupados & $2.309,87$ & $26,5 \%$ & 0,60 & 1.386 & $15,9 \%$ \\
\hline Áreas Verdes dentro do Lote & 135,42 & $1,6 \%$ & 0,21 & 28 & $0,3 \%$ \\
\hline Área Asfaltada & 1936 & $22,2 \%$ & 0,95 & 1.839 & $21,1 \%$ \\
\hline Área ECPP Cerâmica & 261,5 & $3 \%$ & 0,90 & 235,35 & $3 \%$ \\
\hline Área ECPP Concreto & 582,06 & $7 \%$ & 0,95 & 552,957 & $6 \%$ \\
\hline Faixa Gramada & 21,6 & $0 \%$ & 0,21 & 4,536 & $0 \%$ \\
\hline & & & Fonte: Autora (2015) &
\end{tabular}

A Tabela 4 mostra os resultados do cenário real da microbacia do ECPP Bairro, a microbacia de área de $8.721,74 \mathrm{~m}^{2}$, tem uma área de contribuição para o escoamento superficial de $7.348 \mathrm{~m}^{2}$, sendo proveniente cerca de $9 \%$ dos ECPPs cerâmica e concreto.

O cenário favorável indicado na Tabela 5 , contribui com $4.752 \mathrm{~m}^{2}$ para o escoamento superficial, desta área somente $2 \%$ é de contribuição dos ECPPs.

\begin{tabular}{l|l|l|l|l|l}
\hline & & & & Tabela 2 - Cenário favorável \\
CARACTERísTICAS ECPP & $\mathrm{m}^{2}$ & $\%$ & $\begin{array}{l}\text { Coeficiente de } \\
\text { escoamento }\end{array}$ & $\begin{array}{l}\text { Área de Contribuição para } \\
\text { o escoamento superficial } \\
\left(\mathrm{m}^{2}\right)\end{array}$ & $\begin{array}{l}\text { Escoamento } \\
\text { Superficial }\end{array}$ \\
\hline Área Microbacia & $8.721,74$ & $100,0 \%$ & & 4.752 & $54,5 \%$ \\
\hline Lotes Ocupados & $5.032,49$ & $57,7 \%$ & 0,50 & 2.516 & $28,9 \%$ \\
\hline Áreas Verdes dentro do Lote & 888,08 & $10,2 \%$ & 0,21 & 186 & $2,1 \%$ \\
\hline Área Asfaltada & 1936 & $22,2 \%$ & 0,95 & 1.839 & $21,1 \%$ \\
\hline Área ECPP & 865,16 & $10 \%$ & 0,21 & 181,6836 & $2 \%$ \\
\hline Total Faixa Gramada & 133,36 & $2 \%$ & 0,21 & 28,0056 & $0 \%$ \\
\hline & & \multicolumn{7}{|c}{ Fonte: Autora $(2015)$} &
\end{tabular}

A Tabela 6 mostra os resultados da aplicação de um cenário desfavorável. Neste cenário a área de contribuição para o escoamento superficial é de $8.412 \mathrm{~m}^{2}$, e desta área $11 \%$ é proveniente dos ECPP. 


\section{Revista Nacional de}

Gerenciamento de Cidades

National Journal of Cities Management

Tabela 3 - Cenário desfavorável

\begin{tabular}{l|l|l|l|l|l}
\hline $\begin{array}{l}\text { CARACTERÍSTICAS } \\
\text { ECPP }\end{array}$ & $\mathrm{m}^{2}$ & $\%$ & $\begin{array}{l}\text { Coeficiente de } \\
\text { escoamento }\end{array}$ & $\begin{array}{l}\text { Área de Contribuição para o } \\
\text { escoamento superficial }\left(\mathrm{m}^{2}\right)\end{array}$ & $\begin{array}{l}\text { Escoamento } \\
\text { Superficial }\end{array}$ \\
\hline Área Microbacia & $8.721,74$ & $100,0 \%$ & & 8.412 & $96,5 \%$ \\
\hline Lotes Ocupados & $5.920,58$ & $67,9 \%$ & 0,95 & 5.625 & $64,5 \%$ \\
\hline Área Asfaltada & 1.936 & $22,2 \%$ & 0,95 & 1.839 & $21,1 \%$ \\
\hline Área ECPP & 998,52 & $11 \%$ & 0,95 & 948,594 & $11 \%$ \\
\hline
\end{tabular}

Na Tabela 7, são apresentados a síntese dos cenários do ECPP Bairro, no cenário real os ECPPs correspondem a cerca de $9 \%$ da contribuição para o escoamento superficial, cenário muito próximo ao cenário desfavorável em que o ECPP contribui em $11 \%$ para o escoamento superficial, onde os ECPPs são considerados $100 \%$ impermeabilizados por concreto convencional. No cenário favorável, o escoamento da água de chuva direcionado para as faixas gramadas, considerando que todas as edificações atendem a este critério, os ECPPs contribuem apenas em $2 \%$ para o escoamento superficial.

Tabela 4 - Síntese dos cenários

\begin{tabular}{|c|c|c|c|c|c|c|c|c|}
\hline \multirow[b]{2}{*}{$\begin{array}{l}\text { CARACTERÍSTICAS } \\
\text { DO ECPP }\end{array}$} & \multirow[b]{2}{*}{$\mathrm{m}^{2}$} & \multirow[b]{2}{*}{$\%$} & \multicolumn{2}{|l|}{ Cenário Real } & \multicolumn{2}{|c|}{ Cenário Favorável } & \multicolumn{2}{|c|}{ Cenário Desfavorável } \\
\hline & & & $\begin{array}{l}\text { Área de } \\
\text { Contribuição } \\
\text { para o } \\
\text { escoamento } \\
\text { superficial }\left(\mathrm{m}^{2}\right)\end{array}$ & $\begin{array}{l}\text { Escoamento } \\
\text { Superficial }\end{array}$ & $\begin{array}{l}\text { Área de } \\
\text { Contribuição } \\
\text { para o } \\
\text { escoamento } \\
\text { superficial } \\
\left(\mathrm{m}^{2}\right)\end{array}$ & $\begin{array}{l}\text { Escoamento } \\
\text { Superficial }\end{array}$ & $\begin{array}{l}\text { Área de } \\
\text { Contribuição } \\
\text { para o } \\
\text { escoamento } \\
\text { superficial } \\
\left(\mathrm{m}^{2}\right)\end{array}$ & $\begin{array}{l}\text { Escoamento } \\
\text { Superficial }\end{array}$ \\
\hline Área de Estudo & 8.722 & $100 \%$ & 7.348 & $84 \%$ & 4.752 & $54 \%$ & 8.412 & $96 \%$ \\
\hline $\begin{array}{l}\text { Área de Lotes } \\
\text { ocupados }\end{array}$ & 3.475 & $40 \%$ & 3.302 & $38 \%$ & 2.516 & $29 \%$ & 5.625 & $64 \%$ \\
\hline $\begin{array}{l}\text { Área Lotes não } \\
\text { ocupados }\end{array}$ & 2.310 & $26 \%$ & 1.386 & $16 \%$ & - & - & - & - \\
\hline $\begin{array}{l}\text { Áreas Verdes } \\
\text { dentro do Lote }\end{array}$ & 135 & $2 \%$ & 28 & $0 \%$ & 186 & $2 \%$ & - & - \\
\hline Área Asfaltada & 1.936 & $22 \%$ & 1.839 & $21 \%$ & 1.839 & $21 \%$ & 1.839 & $21 \%$ \\
\hline Área ECPP & 844 & $10 \%$ & 788 & $9 \%$ & 182 & $2 \%$ & 949 & $11 \%$ \\
\hline Faixa Gramada & 22 & $0 \%$ & 5 & $0 \%$ & 28 & $0 \%$ & & \\
\hline
\end{tabular}


COUPE, S.J., et al. New developments in permeable pavement design to improve water quantity an quality. Novatech, 2013.

JUNIOR, L. L. C.; BARBASSA, A. P. Parâmetros de projeto de microrreservatório, de pavimentos permeáveis e de previsão de enchentes urbanas. Engenharia Sanitária e Ambiental, Vol. 11, no 1, 4654p. jan/mar, 2006. 